\title{
A study of the impact of athletic scholarship on football achievement motivation of university students
}

\author{
ABDUL RAHMAN BALOGUN MUHAMMED SHITTU* [0
}

School of Humanities, Education and Social Sciences (HESS), Khazar University, Baku, Azerbaijan

\section{RESEARCH PAPER}

Received: November 29, 2019 • Accepted: October 10, 2020

Published online: April 20, 2021

(c) 2021 The Author(s)

\begin{abstract}
Vividly, it is not an overstatement to say that football game is the most prominent sport in the recent world. The present study is about the impact of athletic scholarship on football achievement motivation of university students. Athletic type of scholarship helps students to discover, improve and exhibit their football talent and skills. It makes effective contributions to the development of sport within the campus and prepares ambitious and hardworking college or university athletes for the challenges of actualizing their long-term ambitions to become professional footballers. Considering both empirical cum theoretical contributions of this study, the finding practically provides the following suggestions. 1- the finding pinpoints the insights and importance of athletic scholarship and encourage the stakeholders of the university to cultivate the idea of athletic scholarships by extending their scholarship schemes beyond merit and needy bases. 2- It gives an insight that athletic scholarship enables the students to study any academic program and have tendency of becoming professional footballers. 3- importantly, it adds to the literature by investigating the impact of athletic scholarship on football achievement motivation of the students and how the stardoms of being a footballer in the campus affect the students' football interest.
\end{abstract}

\section{KEYWORDS}

athletic, scholarship, football, achievement, motivation

*Corresponding author. E-mail: abdrahman082000@gmail.com 


\section{INTRODUCTION}

In general, academic scholarships play a crucial role in sustaining students' success, retention and completion of degrees at the higher institutions Wohlgemuth et al. (2007) and Whalen, Sanders, and Shelley (2009). The distributions of institutional scholarships are frequently based on academic ability of the students, which is known as "merit-based" Glocker (2011). Sometimes, scholarship comes in form of grants or and loans for needy and less privileged applicants, this is commonly referred to as "need-based" Singell (2004), and ultimately, scholarships are equally provided in some of the higher institutions based on outstanding skills of individuals for athletics Pascarella and Terenzini (2005). Athletic type of scholarship helps students to discover, improve and exhibit their football talent and skills. It makes effective contributions to the development of sport within the campus and prepares ambitious and hardworking college or university athletes for the challenges of actualizing their long-term ambitions to become professional footballers. Obviously, some national football associations scout for talented footballers within the campuses, this has paved ways for several campus footballers to become global and well-known stars in the football industry.

Apparently, some of the universities with athletic scholarships contribute in one way or the other to the development of global football. As they extend the opportunity to the students with the athletic talents without restrictions. Unlike FIFA and some other scholarships with barriers and restrictions that entertain fewer and usually sideline other category of students. For instance, to secure a scholarship opportunity under the federal international football association (FIFA), the applicant's area of academic interest must be related to sport. In line with the instructions given on Guidelines for the "FIFA Master" scholarship, all the available programs for master's degree such as Law, Humanities and Management are strictly related to sport. Anyways, the above scenario is an indication to the globalization and acceptability of sport, especially football.

The present study explores the role of athletic scholarships as a determinant of students' motivation toward success and retention of their football interest before or upon the completion of their academic degrees at the college on one hand, and the inevitable hindrances of fames and stardoms attached to the athletic and or football roles of the students at the college on the other hand. The reflection of these factors in sustaining their athletic scholarships through the liberation of required sport and football activities, together with the impact of the athletic scholarship on students' ambition to become professional footballers are the bone of contention of the study.

The variations in the criteria in awarding academic scholarships create more opportunities for various students of different talents Toby (2010). Students are not equal in their intellectual capacity, thus; limiting the major academic scholarship criterion on educational merit will be a channel to sideline and discriminate against other type of students with other type of skills. Coonrod (2008) for example, argued that "significant evolution in distribution of academic scholarships in the United States during the past fifty years is due primarily to a powerful statement made by Lyndon Baines Johnson that "Poverty must not be a bar to learning, and learning must be an escape from poverty (Johnson, 1964)." The statements generate a consideration for the needy and those who are blessed with natural and outstanding athleticism among the students, especially in the present age. It is not surprising to say that most of the footballers are not often considered as the snappiest tools in the box when it comes to educational competency. The numbers of educated footballers of the world are insignificant, the reasons for that cannot be dogmatically assumed in the absence of empirical study to justify the assumption. 
Evidently, being an athlete in a college attracts lots of advantages, aside from the eminent academic scholarship opportunity even though the path to it can be long and complicated Ryan (1980). Also, it is an avenue to showcase talent and skills in front of several colleagues and fans. However, Fintor (2013) argues that students who engage in sport activities during their school tenure tend to experience a lot of difficulties. Nevertheless, sustaining this requires both intrinsic and extrinsic motivations. Even though, there is notable ambiguity between motivational theory and empirical evidences on athletic scholarships, but the next paragraphs display theoretical studies on both an intrinsic and an extrinsic motivation.

\section{The capture of motivation}

Of course, findings have pinpointed the two utmost conspicuous concepts for assimilating the processes of motivation in sport sceneries as intrinsic motivation (IM) and extrinsic motivation (EM) (Deci and Ryan, 2002; Vallerand and Rousseau, 2001). According to (Ryan and Deci, 2000), engaging in an activity for the purpose of pleasures and fulfillments and not for some detachable consequence is referred to as intrinsic motivation. While extrinsic motivation underpins the notion of performing an activity not necessarily because of the natural flair and rigor, but for the attainment of certain goal and objective. Therefore, a central motivation or motivated behavior can be best understood in the absence of either intrinsic or extrinsic motivation (Deci and Ryan, 2002). As that said, it indicates a nullification of linkage in individual's actions and outcomes and, emphasizes that human behavior can be influenced by the forces beyond their control (Deci and Ryan, 1985).

Vallerand and Rousseau (2001) classify intrinsic motivation into the following three classifications. Firstly, intrinsic motivation that enables one to understand "engagement regulation in any activity for the satisfaction derived from learning for instance. Secondly, intrinsic motivation that helps to actualize satisfaction and pleasure derived while struggling to get a particular task done or trying to actualize an objective, and the third is an intrinsic motivation as a stimulation of desirable experience which transpires while engaging in any kind of activity just because of its attached pleasures (Vallerand and Rousseau, 2001).

According to (Deci, 1975; Deci \& Ryan, 1985, 1991), people's interaction with the environment in which they live in, is to purposely sense their competency and, for the creation of exceptional actualization. Consequently, some researchers (Deci, 1975; Deci \& Ryan, 1985) projected that intrinsic motivation can be understood through the evaluation of cognitive theory in collaboration with the theory of self-determination.

The study examines the motivational impact of athletic scholarship on university students but majorly, the study adds to the literature as the first empirical study ever to explore the role and impact of university athletic scholarship on students' football achievement motivation as a reflection of their ambitions to become professional footballers. Also, by investigating the effects of stardom and popularity attached to athletic life of students who are the recipients of the scholarship because of their football talent and skill within the campus. These threefold research questions are answered:

1. what are the motivational reasons for the football interest of the university students?

2. what is the impact of athletic scholarship on football achievement motivation of the students?

3. how is the impact of stardom attached to the football motivation on academic achievement of the students? 
Consequently, the following statements were eventually hypothesized:

- Athletic scholarship has positive impact on football achievement motivation of students.

- Stardom attached to the football motivation has negative impact on academic achievement of the students.

\section{METHOD}

The questions of this research posed in this investigation accentuated participants' opinions about motivational reasons for the football interest, the impact of athletic scholarship on their football achievement motivation, and the impact of stardom attached to the football motivation on academic achievement of the students. Thus, the study analyzed and established a variety of designs regarding the investigation of the impact of athletic scholarship on football achievement motivation of the selected population. This chapter scrutinizes the detailed methods for this research. It explicitly discourses the research objectives and design, the instrument and methods for data distribution and collection. Equally, it provides insights with regards to the reliability and/or validity of the adopted instrument of the study, the sample size out of the population, preparation of the data gathered for this empirical research.

The study was majorly conducted using quantitative approach of analysis and finally qualitatively supplemented. Basically, this study addressed two questions that were analyzed quantitatively but, a qualitative method through semi-structured interviews of the control group of the study were correspondingly adopted as supplementary in order to attain detailed information on the second question of the study.

Regarding the qualitative aspect of the study, data were collected through an adopted instrument of The Sport Motivation Scale (SMS). SMS is an instrument initially invented by Pelletier et al. (1995), and later reconstructed by Mallett, Kawabata, Newcombe, Otero-Forero, and Jackson (2007). The participants were all male between 15 and 25 years of age. The study targeted both undergraduates and few first-year master students. The permission for the adoption of the instrument was obtained from one of the inventors Otero-Forero, to ensure the promotion of ethical process in academic research.

The administration of the (SMS) questionnaires to the control group in this study was a bit challenging due to the location and the participants distance, and this necessitates the assignment and engagement of an active representative. The questionnaires were distributed to the footballers among the athletes of International Islamic University Malaysia (IIUM). Noteworthily, there are two types of footballers in the athletic club of IIUM. The first category (group A) is set of footballers who are selected based on their eligibility and awarded the athletic scholarship to further their higher education in the university with the agreement to use their football talent and skills to promote the IIUM football team. The second category (group B) is that of footballers who voluntarily join the football club i.e. non-recipients of athletic scholarship. They probably join to improve their skills, to showcase their talent, or because of their natural interest in football.

A number of 84 questionnaires were distributed and collected from the two categories as stipulated above. Forty-six from group-a (i.e. athletic scholarship recipients) and 38 from group-b (non-athletic scholarship recipients) of the study. The data distribution was done 
randomly with the assistance of a representative who was purposely assigned for the distribution and collection of the data, and importantly to ensure that each questionnaire was administered by the statistical appropriately selected individual. The athletic football club encompasses both undergraduate and postgraduate students of the university and they were accessed through the admission office and Centre for Postgraduate Students (CPS) of International Islamic University Malaysia (IIUM). Subsequently, the interview was conducted through the telephone, Skype, and WhatsApp for the analysis of a supplement qualitative research question of the study.

The interview responses were accurately recorded and transcribed equally. However, it is relevantly important to declare that, the interview was solely semi-structured for the two subgroups A (athletic scholarship recipients) and B (non-recipients of athletic scholarship) of the control group.

Regarding the validity, which according to Gay (1992) enables researcher to induce appropriate, eloquent and useful inferences; and reliability of the (SMS) instrument, of which high reliability indicates that items measuring the same construct are highly inter-correlated Hair, Anderson, Tatham, and Black (1998). Several studies from different part of the world such as UK (Hamer, Karageorghis, \& Vlachopoulos, 2002; Ntoumanis, 2001), New Zealand cum Australia (Jackson, Kimiecik, Ford, \& Marsh, 1998), Greek (Alexandris, Tsorbatzoudis, \& Grouios, 2002; Doganis, 2000; Goergiadis, Biddle, \& Chatzisarantis, 2001) and France (Sarrazin, Vallerand, Guillet, Pelletier, \& Curry, 2001) confirmed the validity and the reliability of the instrument.

\section{Data analysis}

To understand the phenomenon cum motives that trigger the interest of IIUM football club and the impact of athletic scholarship on their achievement motivation, the selected items from SMS went through various types of analyses in SPSS. The study generates a non-evaluative analysis of the findings that were based on the quantitative data gathered from the adopted instrument and responses obtained from the moderately conducted interviews.

Generally, frequency analysis was done on the two selected subgroups of the study for the establishment of general understanding about the influential motives for football interest of the control group. Subsequently, the data was explored to understand the football motivation of the two groups in a separate dimension. Based on that, the thematic analyses of supplementary semi-structure interview were presented for detailed information regarding their motives towards the football in the university. Finally, to explore the significant value for the impact of athletic scholarship among the IIUM footballers, regression analysis of the data was considered.

\section{RESULTS}

The main results from this research have been emphasized as follow. In providing insights into football motivation among the entire control group, the frequency explorations of 4 highly significant motives out of (11) ground total of the items selected for the football motivational measurement were provided.

The pleasure the IIUM footballers feel while acquiring training techniques was regarded as the most influential motive. This is because 86.9 percent of the participants admitted that the motive corresponds to their engagement in the university football team, 10.7 percent confirmed 
that it corresponds moderately and only 2.4 percent claimed that it does not correspond at all (see Table 1).

In line with that, another highly significant motive was noted as satisfactory experiences they enjoy during the constant trainings which provide them with the regular opportunities to perfect their football abilities. Thus, the total percentage of the participants who agreed that the motive corresponds in totality was $83.3,14.3$ agreed that it corresponds moderately, while just 2.4 of the participants disagreed (see Table 2).

The third motive according to the frequency analysis was reported as the negative feelings they developed when they were not taking time to do it. This motive found slightly significant as 58.3 percent proved that it corresponds exactly, to 28.6 percent of the participants it corresponds moderately and those who did not see it to correspond at all were 13.1 percent of the control group (see Table 3 ).

In addition, motive that they must do sport in order to feel good about themselves was found relatively and slightly corresponds exactly to IIUM footballers as it was affirmed by 52.4 percent. Another 38.1 percent equally believed that the motive corresponds moderately, while 9.5 argued that it does not in any way correspond to their football motivation (see Table 4).

An overview of the four significant motives for both groups: 1- athletic scholarship recipients and 2- athletic non-scholarship recipients, the voluntary athletes who joined the university football club for other personal reason has been addressed as stipulated above. Subsequently, the following paragraphs discuss the differences and similarities in the motives that influence the

Table 1. Motive-for the pleasure that I feel while learning training techniques that I have never tried before

\begin{tabular}{|c|c|c|c|c|c|}
\hline & & Frequency & Percent & Valid percent & Cumulative percent \\
\hline \multirow[t]{4}{*}{ Valid } & Does not correspond at all & 2 & 2.4 & 2.4 & 2.4 \\
\hline & Corresponds moderately & 9 & 10.7 & 10.7 & 13.1 \\
\hline & Corresponds exactly & 73 & 86.9 & 86.9 & 100.0 \\
\hline & Total & 84 & 100.0 & 100.0 & \\
\hline
\end{tabular}

Table 2. Motive-for the satisfaction I experience while I am perfecting my abilities

\begin{tabular}{|c|c|c|c|c|c|}
\hline & & Frequency & Percent & Valid percent & Cumulative percent \\
\hline \multirow[t]{4}{*}{ Valid } & Does not correspond at all & 2 & 2.4 & 2.4 & 2.4 \\
\hline & Corresponds moderately & 12 & 14.3 & 14.3 & 16.7 \\
\hline & Corresponds exactly & 70 & 83.3 & 83.3 & 100.0 \\
\hline & Total & 84 & 100.0 & 100.0 & \\
\hline
\end{tabular}

Table 3. Motive-because I would feel bad if I was not taking time to do it

\begin{tabular}{cccccc}
\hline & Frequency & Percent & Valid percent & Cumulative percent \\
\hline Valid & Does not correspond at all & 11 & 13.1 & 13.1 & 13.1 \\
& Corresponds moderately & 24 & 28.6 & 28.6 & 41.7 \\
& Corresponds exactly & 49 & 58.3 & 58.3 & 100.0 \\
Total & 84 & 100.0 & 100.0 & \\
\hline
\end{tabular}


Table 4. Motive-because I must do sports to feel good about myself

\begin{tabular}{|c|c|c|c|c|c|}
\hline & & Frequency & Percent & Valid percent & Cumulative percent \\
\hline \multirow[t]{4}{*}{ Valid } & Does not correspond at all & 8 & 9.5 & 9.5 & 9.5 \\
\hline & Corresponds moderately & 32 & 38.1 & 38.1 & 47.6 \\
\hline & Corresponds exactly & 44 & 52.4 & 52.4 & 100.0 \\
\hline & Total & 84 & 100.0 & 100.0 & \\
\hline
\end{tabular}

football interest of the IIUM athletic students in accordance with the grouping strategy of the study. The sport was motivation of the participants and was tested through 11 items selected from Sport Motivation Scale (SMS) and for the list of the selected items (see Table 5).

Table 5 has clearly displayed the adopted items for the measurement of footballers' motivation. Therefore, this paragraph did not encompass the whole 12 items rather, few items were selected in view of their importance. Item number one is about (having previously good reasons for doing sports, but presently asking if he should continue doing it). The mean $=1.09$ for the

Table 5. Selected (11) items from the Sport Motivation Scale

\begin{tabular}{|c|c|c|c|}
\hline 11 Items & Mean-group A & Mean-group B & $N$ \\
\hline $\begin{array}{l}\text { 1. I used to have good reasons for doing sports, but now I } \\
\text { am asking myself if I should continue doing it. }\end{array}$ & 1.09 & 2.89 & 84 \\
\hline 2. Because I must do sports to feel good about myself. & 2.35 & 2.53 & 84 \\
\hline $\begin{array}{l}\text { 3. For the satisfaction I experience while I am perfecting } \\
\text { my abilities. }\end{array}$ & 2.93 & 2.66 & 84 \\
\hline $\begin{array}{l}\text { 4. Because it is a good way to learn lots of things which } \\
\text { could be useful to me in other areas of my life. }\end{array}$ & 2.07 & 2.47 & 84 \\
\hline $\begin{array}{l}\text { 5. For the intense emotions that I feel while I am doing a } \\
\text { sport that I like. }\end{array}$ & 2.15 & 2.11 & 84 \\
\hline $\begin{array}{l}\text { 6. It is not clear to me anymore; I don't really think my } \\
\text { place is in sport. }\end{array}$ & 2.09 & 1.95 & 84 \\
\hline 7. Because I would feel bad if I was not taking time to do it. & 2.72 & 2.13 & 84 \\
\hline 8. To show others how good I am at my sport. & 2.13 & 1.18 & 84 \\
\hline $\begin{array}{l}\text { 9. For the pleasure that I feel while learning training } \\
\text { techniques that I have never tried before. }\end{array}$ & 2.89 & 2.79 & 84 \\
\hline $\begin{array}{l}\text { 10. Because I like the feeling of being totally immersed in } \\
\text { the activity. }\end{array}$ & 2.20 & 2.00 & 84 \\
\hline $\begin{array}{l}\text { 11. I often ask myself; I can't seem to achieve the goals that I } \\
\text { set for myself. }\end{array}$ & 1.17 & 2.89 & 84 \\
\hline
\end{tabular}


first group of the study (the recipients of athletic scholarship). This explored data analysis shows that, this reason does not correspond to the group, unlike the case of the second group (footballers without athletic scholarship), where mean $=2.89$. the second item measures the necessity of doing sports to feel good about oneself. This motive was found relevant to the two groups with slightly higher significant mean (2.53) for the group B -footballers without athletic scholarship-; while the mean $=2.35$ for the footballers and the (group A) recipients of the athletic scholarship. Concerning the third item, it accurately corresponds sport motivation of both groups. For the group A, the mean $=2.93$ and $m=2.66$ for the group B which indicates reverse of the case in the second item. Importantly, the last item reads "they often ask themselves; they cannot seem to achieve the goals that they set for themselves". It is noteworthy to state that this motive has a significant effect with $m=2.89$ on the group of voluntary footballers without athletic scholarship. Meanwhile, it does not really correspond to the footballers who are the recipients of the athletic scholarship.

Consequently, after the understanding and confirmation of necessary assumptions that make regression analysis suitable for the data, the impact of athletic scholarship on football achievement motivation of students was tested using multiple regression analysis. Empirically, the multiple regression was run on the both groups separately in accordance to their scholarship status to predict the effect of athletic scholarship and the impact on footballers' motivation. This variable signifies $\mathrm{F}(11,72)=97.235, P<0.0005, R^{2}=0.937$. Which is an indication of statistical and significant impact of the athletic scholarship on the Group A: footballers/recipients of the athletic scholarship (see Tables 6 and 7).

Based on the findings derived from the adopted instrument of sports motivation scale (SMS), especially for specific items like 1, 4, 6, 7 and 11 (see Table 5); supplementary interviews were conducted across the relevant participants as highlighted in methodology of the study to obtain valuable cum detailed information to establish empirical justifications for this study. The responses of the interviewees were coded thematically, and the interpretations were done and accurately presented under the discussion.

Table 6. The results of the ANOVA ${ }^{\mathrm{a}}$

\begin{tabular}{lcccccc}
\hline Model & & Sum of Squares & df & Mean Square & F & Sig. \\
\hline 1 & Regression & 19.497 & 11 & 1.772 & 97.235 & $0.000^{\mathrm{b}}$ \\
& Residual & 1.312 & 72 & 0.018 & & \\
& Total & 20.810 & 83 & & & \\
\hline
\end{tabular}

${ }^{a}$ Dependent Variable: Athletic Scholarship.

b Predictors: (Selected Items from SMS).

Table 7. Model summary ${ }^{\mathrm{b}}$

\begin{tabular}{lccccc}
\hline Model & $\mathrm{R}$ & $\mathrm{R}$ square & Adjusted R square & Std. error of the estimate & Durbin-Watson \\
\hline 1 & $0.968^{\mathrm{a}}$ & 0.937 & 0.927 & 0.135 & 1.892 \\
\hline
\end{tabular}




\section{DISCUSSION}

This empirical study aims at investigating the impact of athletic scholarship on football achievement motivation of the higher institution students. Besides, the study explores the possible contributions of this scholarship to the football industry at large. The athletic students of the International Islamic University Malaysia (IIUM) were sampled as the participants of this study. The university (IIUM) has a standardized sport complex for both male and female students. The complex contains an Olympic size swimming pool and the international standard football pitch (see Fig. 1).

The IIUM sport unit was establish in 1983 and the role of sport at IIUM has emerged vibrantly. Both the quantity and quality of the IIUM sport activities increased drastically in 1991, and the role of sports became more demanding as a result of the IIUM involvement with the following prominent sports councils and federations: 1- "The World University Sport Federation", 2- "Asian University Sports Federation”, and "Asian University Sports Council" SDC Handbook (2017).

Among the various athletic teams, the football team of the IIUM was chosen for this study. The participants, (i.e. IIUM football team) were systematically grouped into two categories according to their athletic scholarship's status and this categorization was used as the basis of research analysis and particularly to figure out the impact of the athletic scholarship on students' football achievement motivation. Consequently, Table 5 has outlined the frequencies of what motivate the athletic students of IIUM concerning their football achievement motivation. There were collaborations in the responses of the two categories of the study as regard to about seven items of SMS survey instrument. However, the result portrays variations in four of the items which was one of the tangible and logical reasons for the induction of the supplementary interviews. The group B of the study, (i.e. non-recipients of athletic scholarship) those students who voluntarily joined the university (IIUM) football team without any initial agreement of athletic scholarship claimed $(m=2.89)$ that, they use to have great reasons for their willingness

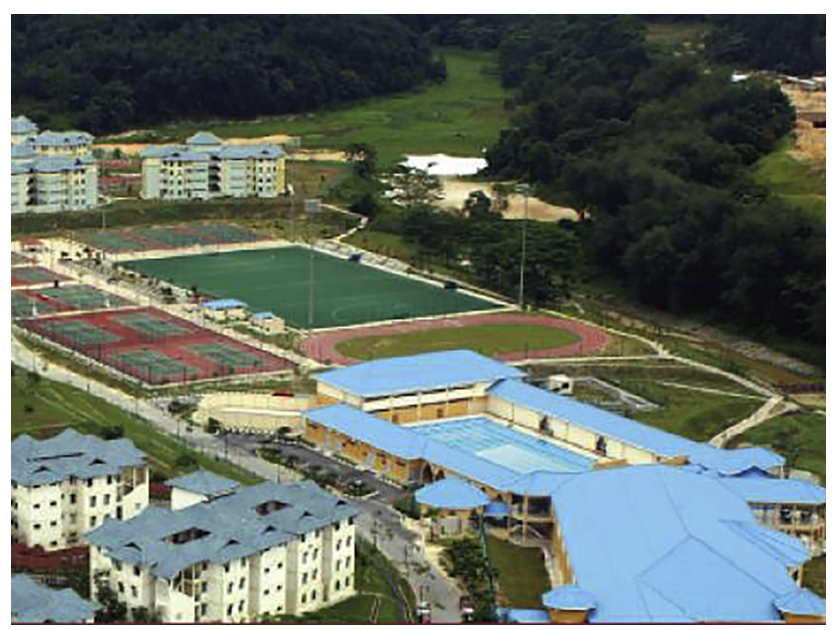

Fig. 1. The IIUM sports complex 
to participate in university football activities; but they currently confused and keep asking themselves if they should continue. Simultaneously, they confirmed that $(m=2.89)$ they often ask themselves they cannot seem to achieve the goals they set for themselves. Although, the case was not the same for the university selected footballers who are the bonafade recipients of the athletic scholarship as shown in their responses of $m=1.09$ in the first item and $m=1.17$ in the second item. However, a surprising response was found regarding their agitation that, it is not clear to them anymore; they do not really think their place is in football. The mean of their response was slightly higher $(m=2.09)$ compared to the second group where their mean value was reported as $m=1.95$.

Additionally, the selected four items were repeatedly used to test the impact of athletic scholarship on the first (athletic scholarship recipients) and the second (non-recipients) subgroups. Table 6 has provided the result of multiple regression analysis, which indicates the statistically significant of the athletic scholarship on its recipients tagged as the group A of the control group in this study. Apparently, the result has proven that athletic scholarship contributes to higher level of football achievement motivation of the athletic scholarship recipients. Tabachnick and Fidell (2001) have previously projected in findings of another similar research.

Concerning the thematic coding for the supplementary interviews, the non-athletic scholarship recipients were interviewed regarding the major reasons for their pronouncement on the

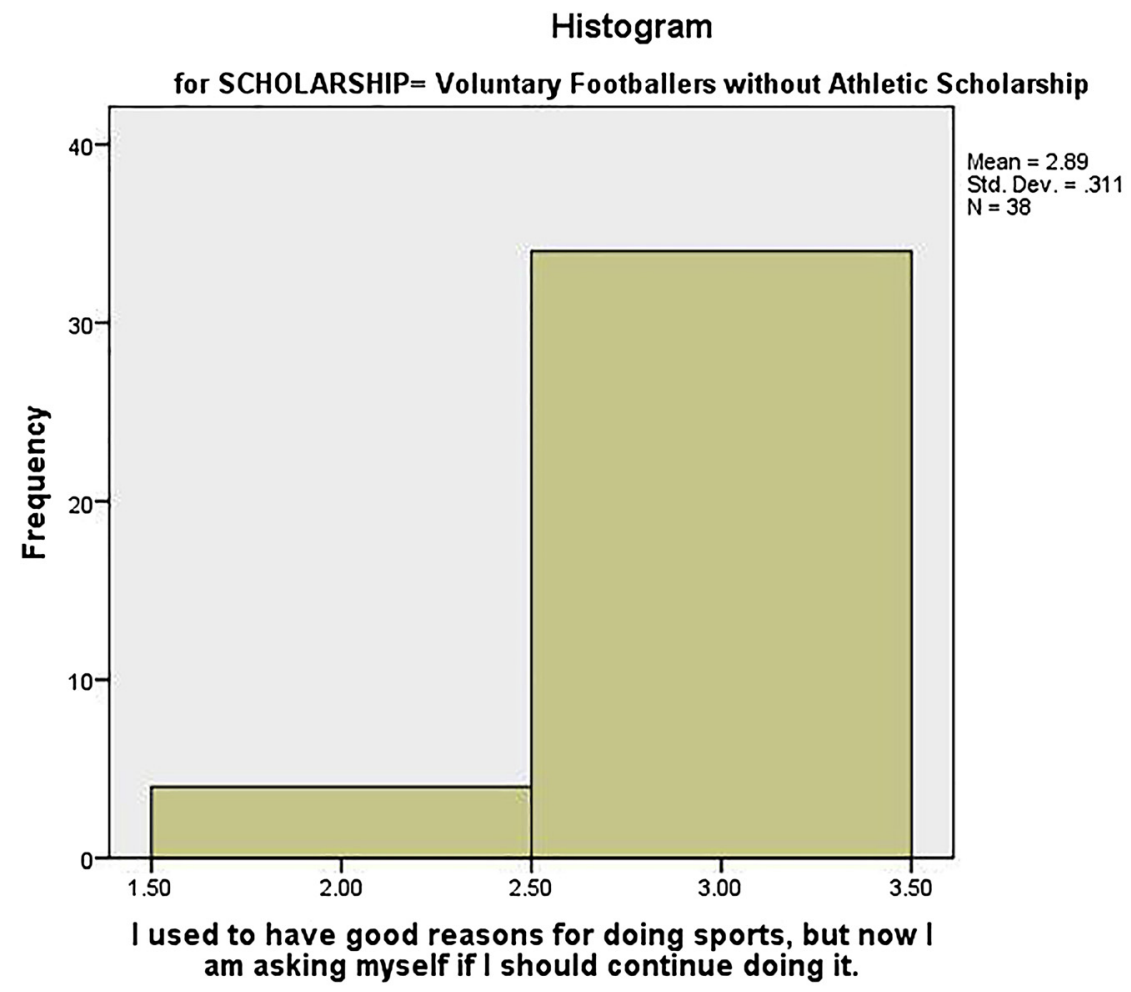

Fig. 2. Histogram for non-athletic scholarship recipients 
fact that; "they use to have good reasons for doing sport but currently asking themselves if they should continue". To shed more insights to this point, the mean values of the voluntary footballers without athletic scholarship (group B, i.e. non-athletic scholarship recipients) are compared and provided in histogram, (check Fig. 2).

A theme was formulated through the responses of a substantial number in the group B as "hidden anticipation". There was a declaration that they voluntarily joined the IIUM football team with the intention of securing the athletic scholarship later through the exhibition of their football skills and performances. This is systematically interrelated, and it can be best explained through the expectancy theory Vroom (1964) which is the model designed to determine choice in responsibilities, tasks, and the level of efforts that help an individual to actualize the utmost intended goals and benefits (Kanfer, 1990). Failure to get this achieved is allegedly demoralizing the group and imperatively cultivating negative feelings in their minds, perhaps as a result of unfairness this group B of campus footballers sensed whether the IIUM sport and/or football management treat them fairly or not. According to (Greenberg, 1997; Greenberg \& Colquitt, 2005), the sensed fairness of the methods applied to maintain resources is described as procedural justice which is the major concept of equity theory. The recipients of athletic scholarship were equally interviewed to establish a clarification and justification on their claim that, "it is not clear to them anymore, and they do not really think their place is in football". Correspondingly, the mean values of the two subgroups were equally compared, and the histogram's boxplots is presented, (check Fig. 3).

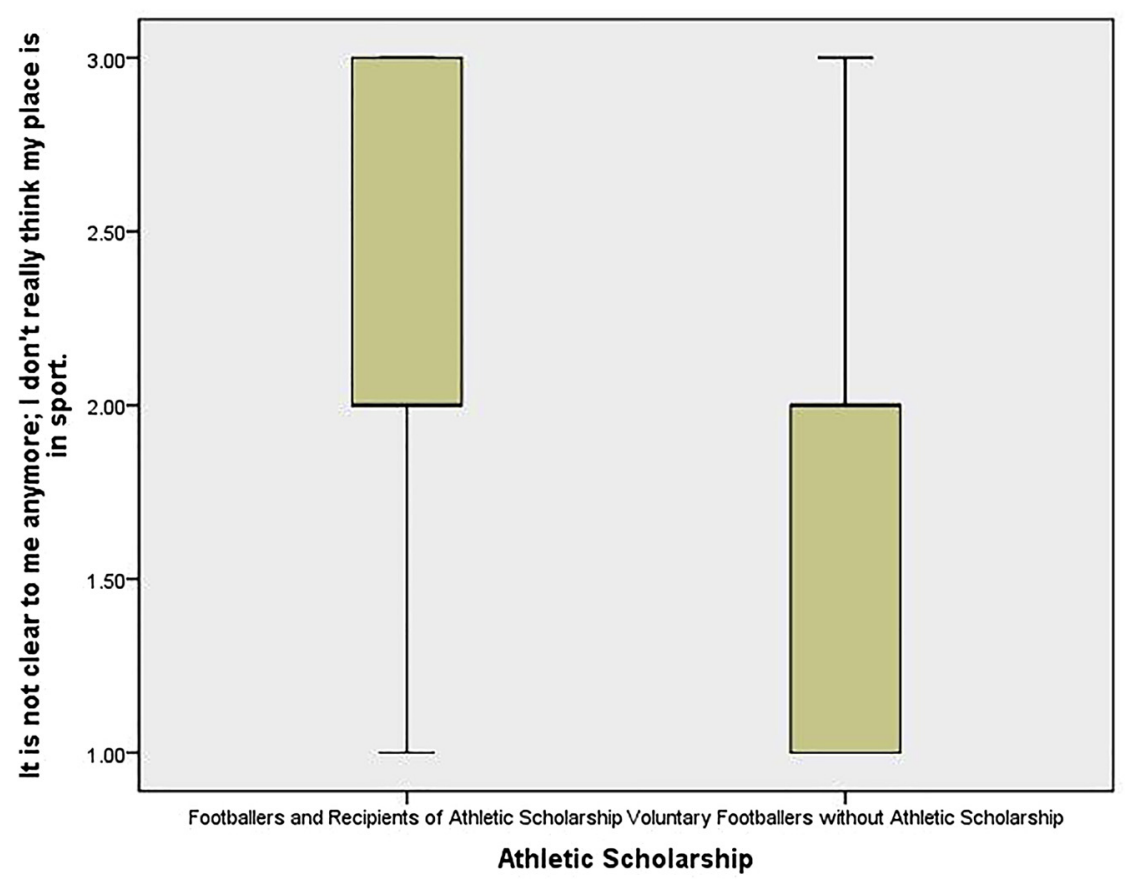

Fig. 3. Histogram's boxplots of the two subgroups compared means 
Furthermore, long-term ambition was identified as another thematic coding due to the interviewees' rejoinders that apart from the motivational advantages attached to the athletic scholarship, they had their long-term ambition which has to do with the interest to become professional footballers. This is somewhat similar to the finding of early study (Fort and Quirk, 1999). However, the two subgroups agree the theme that "the stardom accompanying being a footballer in the campus enhances their interest and boosts their determination to aim at becoming professional footballers. To sum up, based on the both the quantitative findings and the qualitative interpretation of this study; the researcher has pinpointed the contributions of this study to the existing literature and projected some recommendations in the subsequent paragraph.

Considering both the empirical cum the theoretical contributions of this study, the findings practically provide the following suggestions. 1- the findings pinpoint the insights and importance of athletic scholarship and encourage the stakeholders of the general university to cultivate the idea of athletic scholarships by extending their scholarship schemes beyond merit and needy bases. 2- It gives an insight that athletic scholarship enables the students to study and specialize on any academic program and equally have tendency of becoming professional footballers. 3importantly, it adds to the literature by investigating the impact of athletic scholarship on football achievement motivation of the students and how the stardoms of being a footballer in the campus affect the students' football interest.

Funding sources: No financial support was received for this study.

Author's contribution: The author had full access to all data in the study and take responsibility for the integrity of the data and the accuracy of the data analysis, study concept and design, statistical analysis, study supervision, interpretation of data.

Conflict of interest: The author declares no conflict of interest.

Ethics: The study procedures were carried out in accordance with the Declaration of Helsinki. The Institutional Review Board of the Institute of Educational and Cultural Sciences (International Islamic University Malaysia) approved the study.

\section{ACKNOWLEDGEMENTS}

I wholeheartedly acknowledge the support of the entire management of IIUM Sport Complex, the control group, and every individual who took a part in ensuring the success of this project.

\section{ABOUT THE AUTHOR}

A-RBM-S was graduated at Al-Azhar University, Cairo-Egypt in Arts and Education between 2002 and 2006. His Master of Education was obtained at International Islamic University Malaysia (IIUM) between 2007 and 2009. He has worked at various academic institutions in his home country and abroad. He is currently doing his Ph.D. program and actively contributing to 
his department as the educational psychology lecturer at Khazar University, Baku-Azerbaijan. He has participated in many conferences and published some academic papers. He is interested in issues concerning educational psychology, leadership, management, administration and religion.

\section{REFERENCES}

Alexandris, K., Tsorbatzoudis, C., \& Grouios, G. (2002). Perceived constraints on recreational sport participation: Their relationship with intrinsic motivation, extrinsic motivation and amotivation. Journal of Leisure Research, 34, 233-252.

Coonrod, L. (2008). The effects of financial aid amounts on academic performance. The Park Place Economist, 16, 24-25. Retrieved from www.iwu.edu/economics/PPE16/PPE2008-3.pdf.

Deci, E. L. (1975). Intrinsic motivation. Plenum Press. https://doi.org/10.1007/978-1-4613-4446-9.

Deci, E. L., \& Ryan, R. M. (1985). Intrinsic motivation and self-determination in human behavior. New York, NY: Plenum.

Deci, E. L., \& Ryan, R. M. (1991). A motivational approach to self: Integration in personality. In Dienstbier, R. A. (Ed.), Current theory and research in motivation, Vol. 38. Nebraska symposium on motivation, 1990: Perspectives on motivation (pp. 237-288). University of Nebraska Press.

Deci, E. L., \& Ryan, R. M. (2002). Handbook of self-determination research. Rochester, NY: University of Rochester Press.

Doganis, G. (2000). Development of a greek version of the sport motivation scale. Perceptual and Motor Skills, 90, 505-512. https://doi.org/10.2466/PMS.90.2.505-512.

Fintor, J. G. (2013). Correlations of sport levels and popularity of sport programmes among elementary school students. Hungarian Educational Research Journal, 3(3), 67-76. https://doi.org/10.14413/herj. 2013.03.07.

Fort, R., \& Quirk, J. (1999). The college football industry. In J. Fizel, D. Gustafson, \& H. Hadley (Eds.), Sports economics. Westport, CT: Praeger.

Gay, L. R. (1992). Education research competencies for analysis and application. London: Charles E. Milton Keynes Philadelphia Company.

Glocker, D. (2011). The effect of student aid on the duration of study. Economics of Education Review, 30(1), 177-190.

Goergiadis, M. M., Biddle, S. J. H., \& Chatzisarantis, N. L. D. (2001). The mediating role of self-determination in the relationship between goal orientations and physical worth in Greek exercisers. European Journal of Sport Sciences, 1, 1-9.

Greenberg, J. (1997). The STEAL motive: Managing the social determinants of employee theft', in R. Giacalone and J. Greenberg (eds.),. The STEAL Motive: Managing the Social Determinants of Employee Theft.

Greenberg, J., \& Colquitt, J. (2005). Handbook of organizational justice. Mahwah, NJ: Lawrence Erlbaum Associates.

Hair Jr., J. F., Anderson, R. E., Tatham, R. L., \& Black, W. C. (1998). Multivariate data analysis (5th ed.). Upper Saddle River, NJ: Prentice Hall.

Hamer, M., Karageorghis, C. I., \& Vlachopoulos, S. P. (2002). Motives for exercise participation as predictors of exercise dependence among endurance athletes. The Journal of Sports Medicine and Physical Fitness, 42, 233-238. 
Jackson, S. A., Ford, S. K., Kimiecik, J. C., \& Marsh, L. W. (1998). Psychological correlates of flow in sport. Journal of Sport \& Exercise Psychology, 20, 358-378.

Johnson, L. B. (22 May 1964). Great society speech. Graduation. University of Michigan, Ann Arbor. 12 Nov. 2007. http://coursesa.matrix.msu.edu/ hst306/documents/great.html.

Kanfer, R. (1990). Motivation theory and industrial and organizational psychology. In M. D. Dunnette, \& L. M. Hough (Eds.), Handbook of industrial and organizational psychology (pp. 75-170). Palo Alto, CA, US: Consulting Psychologists Press.

Mallett, C. J., Kawabata, M., Newcombe, P., Otero-Forero, A., \& Jackson, S. (2007). Sport Motivation Scale6 (SMS-6): A revised six-factor sport motivation scale. Psychology of Sport and Exercise, 8, 600-614.

Ntoumanis, N. (2001). Empirical links between achievement goal theory and self-determination theory in sport. Journal of Sport Sciences, 19, 397-409.

Pascarella, E. T., \& Terenzini, P. T. (2005). How college affects students: A third decade of research. SanFrancisco, CA: Jossey-Bass.

Pelletier, L. G., Fortier, M. S., Vallerand, R. J., Tuson, K. M., Brie` re, N. M., \& Blais, M. R. (1995). Toward a new measure of intrinsic motivation, extrinsic motivation, and amotivation in ports: The Sport Motivation Scale (SMS). Journal of Sport \& Exercise Psychology, 17, 35-54.

Ryan, E. D. (1980). Attribution, intrinsic motivation, and athletics: A replication and extension. In C. H. Nadeau, W. R. Halliwell, K. M. Newell, \& G C. Roberts (Eds.), Psychology of motor behavior and sport (pp. 19-26). Champaign, IL: Human Kinetics.

Ryan, R. M., \& Deci, E. L. (2000). Intrinsic and extrinsic motivations: Classic definitions and new directions. Contemporary Educational Psychology, 25, 54-67.

Sarrazin, P., Vallerand, R., Guillet, E., Pelletier, L. G., \& Curry, F. (2001). Motivation and dropout in female handballers: A 21-month prospective study. European Journal of Social Psychology, 32, 395-418.

Singell, L. D. (2004). Come and stay a while: Does financial aid effect retention conditioned on enrollment at a large public university? Economics of Education Review, 23(5), 459-471.

Sports Development Centre (07-03-2017). SDC Handbook. Accessed on 07-March-2019, www.iium.edu. my/sports.

Tabachnick, B. Q., \& Fidell, L. S. (2001). Using multivariate statistics (4th ed.). New York, NY: Harper Collins.

Toby, J. (2010). How scholarships morphed into financial aid. Springer, 23, 298-310.

Vallerand, R. J., \& Rousseau, F. L. (2001). Intrinsic and extrinsic motivation in sport and exercise: A review using the hierarchical model of intrinsic and extrinsic motivation. In R. N. Singer, H. A. Hausenblas, \& C. M. Janelle (Eds.). Handbook of sport psychology (2nd ed., pp. 389-416). NY: John Wiley \& Sons.

Vroom, V. H. (1964). Work and motivation. New York: Wiley.

Whalen, D., Saunders, K., \& Shelley, M. (2009). Leveraging what we know to enhance short-term and longterm retention of university students. Journal of College Student Retention: Research, Theory \& Practice, 11(3), 407-430.

Wohlgemuth, D., Whalen, D., Sullivan, J., Nading, C., Shelley, M., \& Wang, Y. R. (2007). Financial, academic, and environmental influences on the retention and graduation of students. Journal of College Student Retention: Research, Theory \& Practice, 8(4), 457-475.

Open Access. This is an open-access article distributed under the terms of the Creative Commons Attribution-NonCommercial 4.0 International License (https://creativecommons.org/licenses/by-nc/4.0/), which permits unrestricted use, distribution, and reproduction in any medium for non-commercial purposes, provided the original author and source are credited, a link to the CC License is provided, and changes - if any - are indicated. 